UDK 528.14

\title{
HEIGHT DETERMINATION TECHNIQUES FOR THE NEXT NATIONAL HEIGHT SYSTEM OF FINLAND - A CASE STUDY
}

\author{
Timo SAARI ${ }^{1}$, Markku POUTANEN ${ }^{2}$, Veikko SAARANEN ${ }^{3}$, Harri KAARTINEN ${ }^{4}$, \\ Antero $\mathrm{KUKKO}^{5}$, Sonja LAHTINEN ${ }^{6}$
}

\author{
Finnish Geospatial Research Institute, Geodeetinrinne 2, FI-02430 Masala, Finland \\ E-mails: ${ }^{1}$ timo.saari@nls.fi (corresponding author); ${ }^{2}$ markku.poutanen@nls.fi; ${ }^{3}$ veikko.saaranen@nls.fi; \\ ${ }^{4}$ harri.kaartinen@nls.fi; ${ }^{5}$ antero.kukko@nls.fi; ${ }^{6}$ sonja.lahtinen@nls.fi
}

Received 15 July 2015; accepted 03 November 2015

\begin{abstract}
Precise levelling is known for its accuracy and reliability in height determination, but the process itself is slow, laborious and expensive. We have started a project to study methods for height determination that could decrease the creation time of national height systems without losing the accuracy and reliability that is needed for them. In the pilot project described here, we study some of the alternative techniques with a pilot field test where we compared them with the precise levelling. The purpose of the test is not to evaluate the mutual superiority or suitability of the techniques, but to establish the background for a larger test and to find strong and weak points of each technique. The techniques chosen for this study were precise levelling, Mobile Laser Scanning (MLS) and Global Navigation Satellite System (GNSS) levelling, which included static Global Positioning System (GPS) and Virtual Reference Station (VRS) measurements.

This research highlighted the differences of the studied techniques and gave insights about the framework and procedure for the later experiments. The research will continue in a larger scale, where the suitability of the techniques regarding the height systems is to be determined.
\end{abstract}

Keywords: national height system, precise levelling, GNSS, VRS, laser scanning, mobile laser scanning, geoid.

\section{Introduction}

For over a century, precise levelling has been the most accurate and reliable height determination technique, although it has its downsides. Creating a national height system with precise levelling is a slow, costly and laborious process, as in Finland it has taken decades every time.

There exist three national height systems in Finland, which have all been based on precise levelling (Lehmuskoski et al. 2008):

- NN: precise levellings in 1892-1910

- N60: precise levellings in 1935-1975

- N2000: precise levellings in 1978-2006 (Fig. 1: levelling network in blue lines).

The field work of the latest national height system in Finland, N2000, was completed in 2006. If another nationwide levelling is needed for the update of the Finnish height system, the field work should be started around 2020. The question arises: is precise levelling replaceable? Few examples already exist, as in New
Zealand and in Canada a gravimetric geoid has been taken in use as the basis of the national height system (Amos 2010; Natural Resources Canada 2015). However, it should be noted that the geography and geodetic infrastructures differ greatly from those in Finland, where the terrain is relatively flat and a dense levelling network extends every part of the country.

In addition to the precise levelling, there are several other techniques to measure heights:

- GNSS levelling - static and Real-Time Kinematic (RTK) / Virtual Reference Station (VRS)

- Terrestrial Laser Scanning (TLS), Mobile Laser Scanning (MLS), Airborne Laser Scanning (ALS)

- satellite altimetry and Synthetic Aperture Radar (SAR) interferometry

- trigonometric levelling

- chronometric levelling.

In this pilot research we concentrated on the ground-based techniques, although impressive results 
have been achieved by SAR interferometry (e.g. Karila et al. 2013). The chosen techniques were precise levelling, MLS and GNSS levelling, including static GPS and VRS measurements. In Finland, the GNSS levelling has been studied for a similar purpose already more than a decade ago (Ollikainen 1997). Since that time, satellite positioning techniques and geoid models have been greatly developed. The use of laser scanning is relatively new approach in this kind of concept.

The main difference between precise levelling and satellite-based techniques is the nature of the measured heights. While precise levelling measures geopotential differences relative to the geoid, satellite-based techniques measure distances (defined along the ellipsoidal normal) from the reference ellipsoid. Therefore one needs a geoid model, containing geoid heights (the height between the reference ellipsoid and the geoid), for converting the geometric ellipsoidal heights to a physically defined gravity based heights.

In practice, a geoid model is often fitted to the existing height system. After this, the GNSS heights converted with this surface will be directly in the correct height system. In Finland the height conversion surface is called FIN2005N00 (Bilker-Koivula, Ollikainen 2009; Bilker-Koivula 2010), which is based on the Nordic geoid model NKG2004 (Forsberg et al. 2004). With FIN2005N00 one can convert GNSS heights to N2000 and vice versa with the accuracy better than $2 \mathrm{~cm}$.

Our aim is to find a method that could dramatically decrease the creation and/or updating time of the national height systems without losing the accuracy and metrological reliability. The purpose of this research is not to evaluate the mutual superiority or suitability of the techniques, but to optimize the procedures for a larger field test and to find strong and weak points of each technique. In the following, we give a short overview of each technique before the description of the field test.

\section{Height determination techniques in this research}

\subsection{Precise levelling}

The principles behind the levelling have not changed in over a century and there are well-defined practices for the measurement procedure. Precise levelling is a special approach with metrologically traceable chain of the scale to the definition of meter, and where computations are made on the level of geopotential. In addition the final corrections to the refraction, tidal and rod are made in the post-processing step. Lower-order

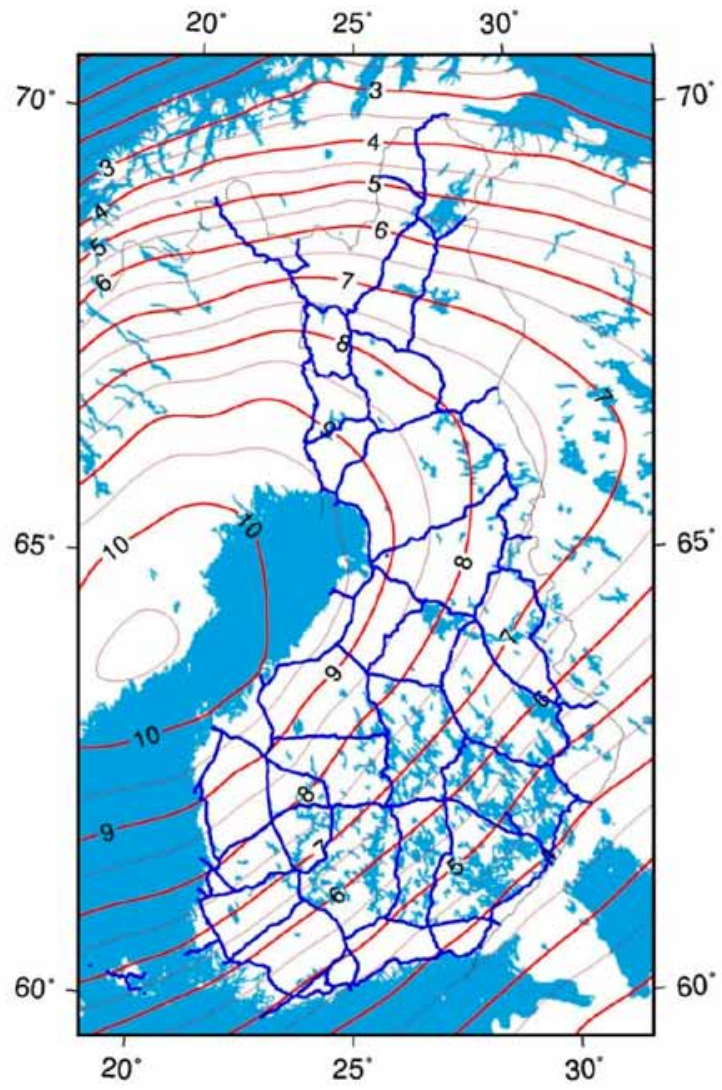

Fig. 1. Postglacial rebound in Finland (red contours), in $\mathrm{mm} /$ year. The contours are from the Nordic uplift model NKG2005LU (Vestøl 2005; Ågren, Svensson 2007), which is relative to the Baltic mean sea level 1892-1991. The model is adjusted in vertical direction to fit the GNSS based absolute uplift rate by Lidberg et al. (2007). The first order levelling network (N2000) is in blue lines

levelling is tied to the network created by the precise levelling.

Although the method itself has not changed, the general research and technical development during the 20th century have brought many improvements in the levelling instruments (e.g. digital level, invar rod) and theories, e.g. the levelling refraction (basic work by Kukkamäki (1938), subsequent e.g. Kharaghani (1987), Ojanen (1996)). A modern version of precise levelling is called motorized levelling, which can speed-up the measurement process by $40-200 \%$ (Becker 1999). In motorized levelling the movement from a benchmark to another is made with vehicles and the observations are performed from the vehicle. Although different kind of semi-motorized techniques have been used as early as 1916 (see Poetzschke 1980), the first modern motorized levellings were conducted in Germany during 1972-1973.

Since 1970s the motorized technique has been used e.g. in Sweden and Germany (Becker 1999), although in Finland it has never been put into service. The method is problematic in Finland since half of the 
precise levelling lines are located at railroads where the use of the motorized levelling is at least troublesome if not impossible (Lehmuskoski et al. 2008). Handcars were used earlier at railroads, but for safety reasons and due to increased train traffic, the use of them is no longer an option.

Advantages and disadvantages related to the precise levelling are listed in Table 1. With precise levelling one obtains the geopotential difference from the geoid to the top of a benchmark. The uncertainties related to the precise levelling are few and relatively less dominant (compared to satellite-based techniques), which results in a good accuracy and reliability. One can model the tidal and refraction effects in measurements, as well as the conversion from geopotential values to metric heights with well-known methods and controllable uncertainties. Regularly calibrated instruments will bring the metrological traceability in the measurements and ties the scale to the definition of metre with known and controllable uncertainty.

Precise levelling is not vulnerable to the surrounding obstructions as the satellite-based techniques are, but only to the obstacles in the line-of-sight. However, surface properties and especially local refraction conditions may be critical, leading to a seasonal dependence. The temperature difference between the ground level and the first few meters of the air should be small and measureable. In Finland the optimal seasons are in April-May and September-October.

The greatest weakness of precise levelling is the nature of the technique which is laborious and slow, meaning the nationwide levelling may take decades. A typical double-run precise levelling distance in Finland is $2 \mathrm{~km} / \mathrm{d}$, but it strongly depends on the topography. In addition to the motorized levelling and digital instruments, the automation of levelling is very modest.

Table 1. Advantages and disadvantages related to precise levelling

\begin{tabular}{|l|l|}
\hline \multicolumn{1}{|c|}{ Advantage } & \multicolumn{1}{c|}{ Disadvantage } \\
\hline $\begin{array}{l}\text { Accuracy, reliability, } \\
\text { traceability }\end{array}$ & Extremely slow \\
\hline $\begin{array}{l}\text { Internationally standardized } \\
\text { method }\end{array}$ & $\begin{array}{l}\text { Dependent on temperature } \\
\text { gradient (refraction) }\end{array}$ \\
\hline $\begin{array}{l}\text { Independent of the } \\
\text { benchmark surroundings }\end{array}$ & Seasonal dependence \\
\hline $\begin{array}{l}\text { Independent of the geoid } \\
\text { model }\end{array}$ & Laborious \\
\hline $\begin{array}{l}\text { Measurements refer on the } \\
\text { top of a benchmark }\end{array}$ & $\begin{array}{l}\text { Costly (years to decades of } \\
\text { work) }\end{array}$ \\
\hline
\end{tabular}

Most of the time is taken when the rods and the instrument are moved from one position to another - this is true also with the motorized levelling.

\subsection{GNSS levelling}

The only global operational GNSSs have been the GPS (realized by the U.S. Department of Defense) and the Russian GLONASS. The situation is now changing, as the European Galileo and Chinese BeiDou are expected to reach their full satellite constellation before 2020 (Lemmens 2012). These will double the number of the positioning satellites.

In this research the GNSS levellings were carried out with static GPS and VRS measurements. VRS was selected as one of the techniques, since it is a commonly used technique in many basic surveying tasks e.g. mapping of power and communication lines or in cadastral and construction work.

Advantages and disadvantages of GNSS and VRS levelling are listed in the Tables 2 and 3. Unlike

Table 2. Advantages and disadvantages related to GNSS levelling

\begin{tabular}{|l|l|}
\hline \multicolumn{1}{|c|}{ Advantage } & \multicolumn{1}{c|}{ Disadvantage } \\
\hline Seasonal independence & $\begin{array}{l}\text { Limited accuracy of the GNSS, } \\
\text { especially in the vertical } \\
\text { component }\end{array}$ \\
\hline Weather independence & Uncertainties in the geoid models \\
\hline $\begin{array}{l}\text { Long measurement } \\
\text { sessions (reliability) }\end{array}$ & $\begin{array}{l}\text { Satellite geometry (benchmark } \\
\text { surroundings) }\end{array}$ \\
\hline $\begin{array}{l}\text { Relatively fast (long } \\
\text { distances) }\end{array}$ & $\begin{array}{l}\text { Information only from the points } \\
\text { of interest }\end{array}$ \\
\hline \multirow{2}{*}{ The amount of GNSS points } \\
\cline { 2 - 2 } & $\begin{array}{l}\text { Uncontrollable uncertainties in } \\
\text { scale (in the sense of metrology) }\end{array}$ \\
\hline
\end{tabular}

Table 3. Advantages and disadvantages related to VRS levelling

\begin{tabular}{|c|c|}
\hline Advantage & Disadvantage \\
\hline Seasonal independence & Limited accuracy of the GNSS \\
\hline Weather independence & Uncertainties in the geoid models \\
\hline Inexpensive & Satellite geometry \\
\hline \multirow[t]{4}{*}{ Fast technique } & $\begin{array}{l}\text { The lack of post-processing } \\
\text { (network adjustment) }\end{array}$ \\
\hline & Dependent on the VRS network \\
\hline & $\begin{array}{l}\text { Information only from the points } \\
\text { of interest }\end{array}$ \\
\hline & $\begin{array}{l}\text { Uncontrollable uncertainties in } \\
\text { scale }\end{array}$ \\
\hline
\end{tabular}


precise levelling, GNSS is not seasonal dependent. However, long measurement sessions are required to improve the accuracy and reliability of the technique (Häkli et al. 2008). Despite of the long measurement sessions the technique is relatively fast, since one can use existing permanent GNSS networks or measure multiple points with great distances simultaneously. Temporal variations, like the seasonal effects as well as the random errors can be studied by using the long time series of permanent GNSS stations. Additionally, long-term trends like the effect of the land uplift can be determined from a few years' data of continuously observing GNSS network.

GNSS height determination is sensitive to the ionospheric and tropospheric refraction, which affects to the accuracy of vertical component. Together with the uncertainties of the geoid models, one may end up to centimeter level uncertainty in the height. Uncertainties in the geoid models are absolute uncertainties valid for geoid heights at a point. However, over small distances geoid changes are small and uncertainties of geoid height differences between two points can be assumed to be much smaller.

Another challenging aspect in GNSS measurements is the surrounding obstructions of the benchmarks, which weakens the satellite geometry that is directly related to the accuracy of the method. Even though the solution could be achieved in a poor satellite geometry, one may still need to reject a large part of the data. We have experienced that with a proper handling of data and well controlled analysis, millimeter accuracy is possible to achieve even if most of the data must be rejected (Kallio, Poutanen 2013). Bringing a metrologically controllable scale in the GNSS measurements can be problematic. Steps to change this have been done in a European Metrology Research Program (EMRP) project SIB60, Metrology for long distance surveying (Pollinger et al. 2015).

In addition, one measure the height values only at the points of interest, i.e. all of the spatial changes between the measurement points remain unknown. Furthermore, the number of GNSS points is relatively small compared to that of the levelling benchmarks. However, new points can be measured wherever needed without remeasurement of any other points.

The Virtual Reference Station is an application of the network RTK concept. The advantages and disadvantages related to VRS levelling are mostly the same as in GNSS levelling. The main differences between these two are the accuracy and reliability. The technique, applies the reference network only for computing the correction surface, but the measurement is done relative to one virtual station. This does not allow control for error propagation and it is subject for a gross error without any actual uncertainty estimation due to the lack of the network adjustment. The result from a VRS measurement is typically an average value from several observations, while with the GNSS levelling (static GPS) the result can be an average from thousands of observations and a proper network adjustment.

\subsection{Mobile laser scanning}

The history of laser scanning dates back to the 1970s and 1980s, when National Aeronautics and Space Administration (NASA) developed laser scanning techniques for oceanography, forestry and other applications (see Nelson et al. 1984; Schreier et al. 1985). The first modern laser scanner instruments were introduced in the early 1990s, and since then the laser scanning has been one of the fastest growing techniques in the field of surveying (Hyyppä et al. 2009).

The usage of laser scanning techniques are versatile, as it is used for mapping topography, vegetation, urban areas, infrastructure and other targets of interest. The laser scanning techniques are divided into three categories: terrestrial, airborne and mobile, which is taken here in a closer look.

Mobile Laser Scanning (MLS) is a ground vehicle-based surveying technique where laser scannings are conducted while moving. The movement of the MLS system can be performed with various moving platforms like cars, boats, snowmobiles and specific backpack platforms. The main instruments of MLS systems are laser scanner, GNSS receiver with appropriate antenna and Inertial Measurement Unit (IMU). Additionally other data acquisition sensors and cameras can be included in the system (Kukko et al. 2012).

With the MLS one can produce three-dimensional point clouds from the surrounding objects that are in the range of the on-board laser scanner. The measurement is carried out as the platform moves around, while the GNSS and IMU tracks the platform's trajectory and attitude. The laser scanner transmits laser beams to its surroundings and the three-dimensional coordinates of the surroundings can be determined from the reflecting laser beams (up to one million points per second).

Advantages and disadvantages related to MLS are listed in the Table 4. Superior attributes of the MLS over precise levelling and GNSS are the measurement rate and the mobility of the system, which makes it effortless to measure large areas relatively fast. 
Table 4. Advantages and disadvantages related to mobile laser scanning

\begin{tabular}{|l|l|}
\hline \multicolumn{1}{|c|}{ Advantage } & \multicolumn{1}{c|}{ Disadvantage } \\
\hline Measurement rate & $\begin{array}{l}\text { Limited accuracy of the } \\
\text { GNSS }\end{array}$ \\
\hline $\begin{array}{l}\text { Comprehensive technique } \\
\text { (measures everything in the } \\
\text { range of the laser scanner) }\end{array}$ & Various error sources \\
\hline $\begin{array}{l}\text { Quickly developing } \\
\text { technique }\end{array}$ & $\begin{array}{l}\text { Uncertainties in the geoid } \\
\text { models }\end{array}$ \\
\hline Less laborious (vehicle) & $\begin{array}{l}\text { Weather conditions } \\
\text { (snowfall, rain) }\end{array}$ \\
\hline & Satellite geometry \\
\cline { 2 - 3 } & $\begin{array}{l}\text { Uncontrollable uncertainties } \\
\text { in scale }\end{array}$ \\
\hline
\end{tabular}

Additionally, the development of the laser scanning instruments has been very fast, e.g. the measurement rate (phase-shift from $100 \mathrm{kHz}$ to $1.1 \mathrm{MHz}$ ) and the range (pulse from $200 \mathrm{~m}$ to $6000 \mathrm{~m}$ ) of the laser scanners have been multiplied during the last decade; a commercial example of a system can be found e.g. in (Trimble 2015).

On the other hand, MLS is under the influence of several error sources, caused by the instruments of the system. MLS suffers from the same disadvantages as the GNSS levelling: inaccuracies in geoid model, satellite geometry and positioning techniques. Another challenging aspect is the prevailing weather conditions, since laser beams reflect from raindrops and snowflakes, thus making the observations unusable for scientific purposes.

\section{Field tests}

In the following are presented the test field and the field measurements. The test field was located next to the Finnish Geospatial Research Institute (FGI, previously Finnish Geodetic Institute) in Masala, where height differences between two levelled benchmarks (95011 and 971007) were measured with the techniques described in Section 1. The obtained height differences and reliabilities were compared between the techniques. Figure 2 presents the test field, the location of the benchmarks and the trajectory from the MLS measurements (green dotted curve).

The benchmarks represent typical cases of height benchmarks (on a bedrock), which were established for levelling without considering any GNSS measurements. 95011 is located by a road with relatively open sky at one side, whereas the other side

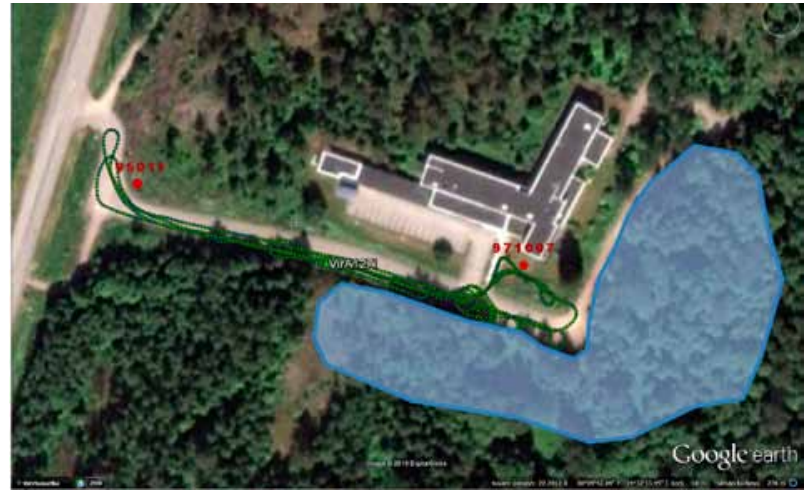

Fig. 2. Aerial photograph of the test field presenting the location of the benchmarks, harvested trees (blue polygon) and the trajectory from the MLS measurements (green dotted curve) (image: Google Earth)

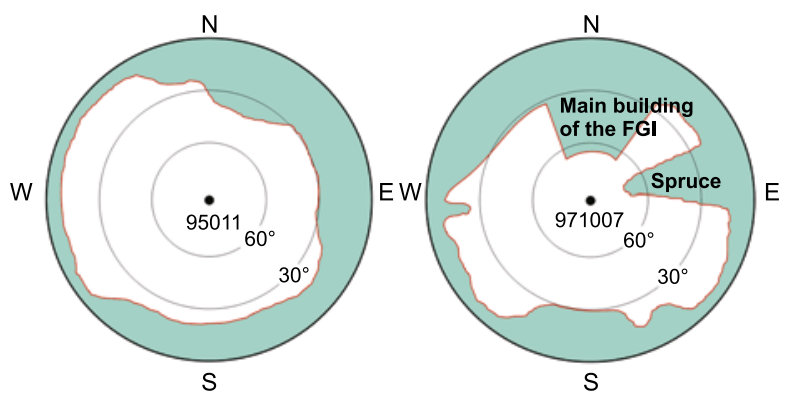

Fig. 3. Sky plots from the benchmarks 95011 and 971007

has more obstructions (Fig. 3). Benchmark 971007 was originally a gravity control point, located near a building (6.56 meters from the building wall) and blocked by a tall tree, making it less suitable for GNSS measurements (Fig. 3). The road between the points is partly obstructed by trees, and the nearby building can be a source of GNSS multipath. The height difference between the points is almost $10 \mathrm{~m}$ and the geoid height differs by $5 \mathrm{~mm}$, thus giving a place for actual evaluation of the techniques. Although the test field is very small, it has all the elements to find out the major concerns of the techniques relative to each other.

\subsection{Test 1: Precise levelling}

The precise levelling was carried out with the Zeiss Dini12 digital level and with two 3 meter invar levelling rods. Temperature values were taken once per minute from 0.5 and 2.5 meters. The observing distances to the back and forth levelling rods were kept equal, while maximum distances were less than 20 meters due to the relatively steep hill. The measurement was performed as a double-run precise levelling.

In this particular case the observed metric height differences were not converted into geopotential 
differences, because of the shortness of the levelling line $(140 \mathrm{~m})$. However, the corrections for the levelling refraction, the rod scale and the tide, were calculated. The results, corrections and uncertainty are presented in the Table 5.

\subsection{Test 2: Static GPS measurements}

The static GPS measurements were carried out twice, where the measurement sessions lasted 7 (I) and 6 hours (II). The measurements were performed with two identical sets of instruments, consisting of Leica GPS receiver, Ashtech choke ring antenna and tripod with tribrach. The observation frequency was set to five seconds.

The slant height between the benchmark and the antenna were measured from three sides before and after the measurement sessions. The post-processing was performed with Bernese GNSS Software v5.2. The results and uncertainties of the sessions are shown in Table 6. In this particular case the uncertainties in the geoid heights were practically eliminated, because the benchmarks were located quite close to each other that the uncertainties in their geoid heights can be assumed equal.

\subsection{Test 3: VRS measurements}

The VRS measurements were carried out with the Trimble R8 GNSS equipment. The observations were performed in five separate days, all of which consisted of two individual measurement sessions, where the benchmarks were observed five times. In total, fifty independent height differences were obtained. The measurement sessions were divided according to the time of the days and different weather conditions, which varied from 2-15 degrees, sunny-cloudy, calm-windy and morning-evening.

The height of the GNSS antenna was set to two meters where the adjustment was made within $\pm 1.0 \mathrm{~mm}$ uncertainty. All the height measurements from the benchmarks are presented in Figure 4. The

Table 5. Results of the precise levelling

\begin{tabular}{|c|c|c|c|c|c|}
\hline \multirow{2}{*}{$\begin{array}{l}\text { Levelling } \\
\text { direction }\end{array}$} & \multicolumn{2}{|c|}{ Corrections } & \multirow{2}{*}{\multicolumn{2}{|c|}{ Observed height difference }} & Corrected \\
\hline & Refraction & Tide & & & difference \\
\hline 95011-971007 & $-0.03 \mathrm{~mm}$ & $0.01 \mathrm{~mm}$ & \multicolumn{2}{|c|}{$9.66140 \mathrm{~m}$} & $9.66125 \mathrm{~m}$ \\
\hline 971007-95011 & $-0.01 \mathrm{~mm}$ & $-0.01 \mathrm{~mm}$ & \multicolumn{2}{|c|}{$-9.66114 \mathrm{~m}$} & $-9.66103 \mathrm{~m}$ \\
\hline \multicolumn{6}{|c|}{ Results } \\
\hline Height difference & Direction difference & \multicolumn{2}{|c|}{ Mean error } & \multicolumn{2}{|c|}{ Systematicality } \\
\hline $9.66114 \mathrm{~m}$ & $0.22 \mathrm{~mm}$ & & & \multicolumn{2}{|c|}{$0.672 \mathrm{~mm} / \mathrm{km}$} \\
\hline
\end{tabular}

Table 6. Results of the static GPS measurements

\begin{tabular}{|c|c|c|c|c|c|c|}
\hline \multirow{2}{*}{ Session } & \multirow{2}{*}{$\begin{array}{c}\text { Height difference } \\
(\mathrm{m})\end{array}$} & \multicolumn{4}{|c|}{ Error estimation (RSS, $\pm \mathrm{mm})$} & \multirow{2}{*}{$\begin{array}{c}\text { Difference } \\
\text { between } \\
\text { sessions }\end{array}$} \\
\cline { 3 - 6 } & & GPS & Slant height & Geoid & Sum & \multirow{2}{*}{$1.6 \mathrm{~mm}$} \\
\hline I & 9.66066 & 3.7 & 0.5 & - & 3.73 & 3.44 \\
\hline II & 9.66226 & 3.4 & 0.5 & - & \\
\hline
\end{tabular}
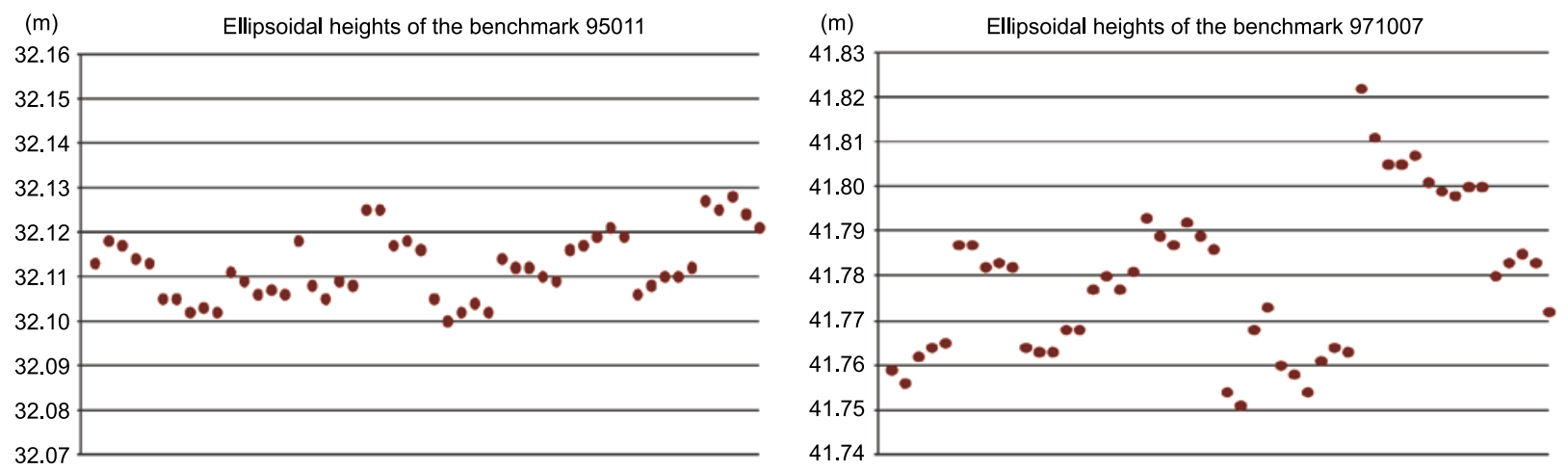

Fig. 4. Variations of the VRS height measurements on the benchmarks 


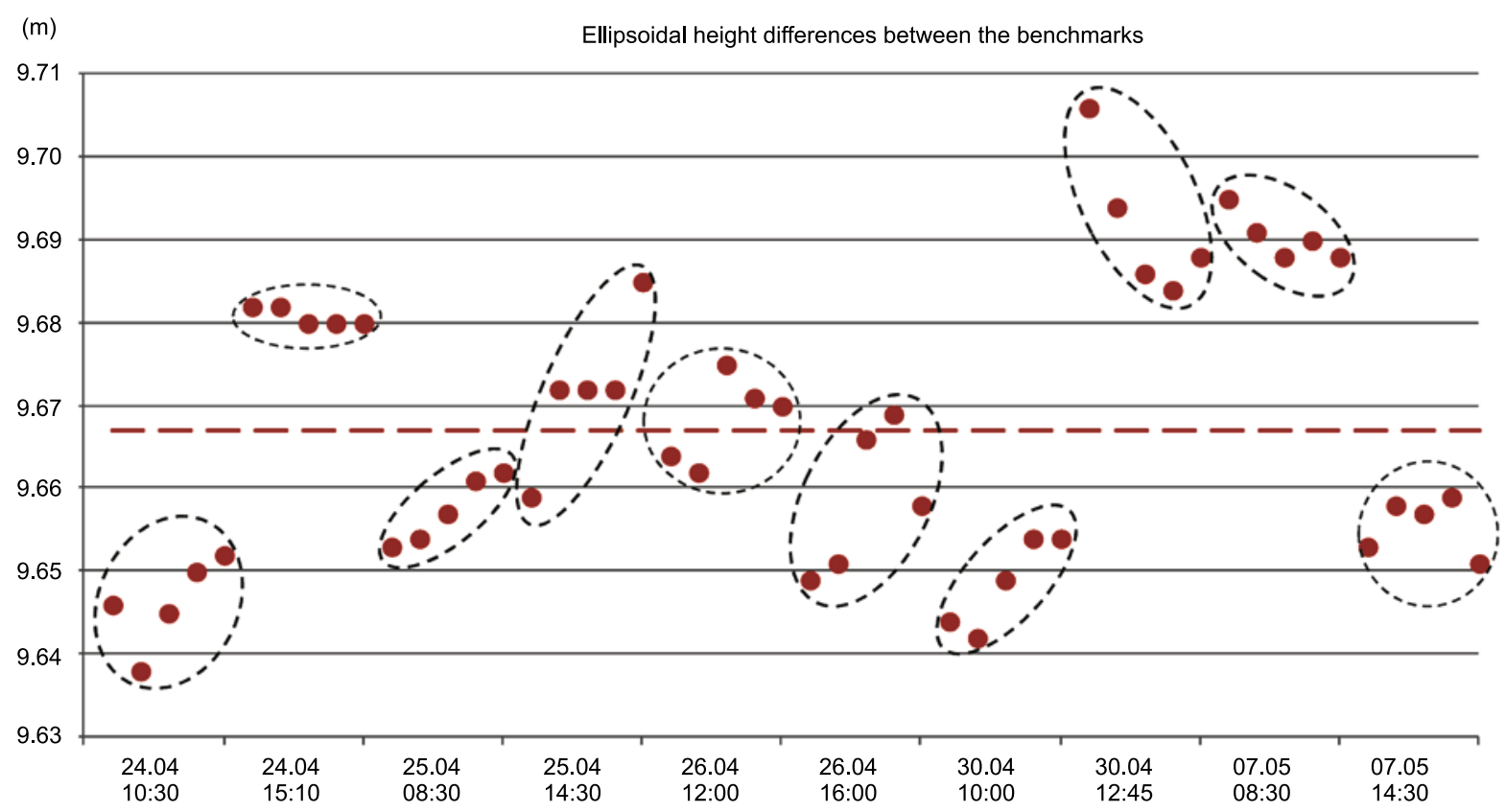

Fig. 5. Ellipsoidal height differences (VRS) between the benchmarks (data of each session enclosed with dotted ellipses)

variation is clearly larger on the benchmark 971007 , which is more affected by the surrounding obstructions (Fig. 3).

A graph of the height differences is presented in Figure 5. The observations are grouped into the sets of five (grey dotted ellipses), which correspond the measurement date and time. The graph indicates that the height differences between the sets are fluctuating a lot. The obstructions at the benchmark 971007 are greatly affecting to the results of the VRS measurements, which can be seen as a correlation between the height differences (Fig. 5) and the variations in 971007 (Fig. 4, right).

\subsection{Test 4: Mobile laser scanning}

The MLS measurement was carried out with the FGI's MLS system called Akhka R2, first introduced in Liang

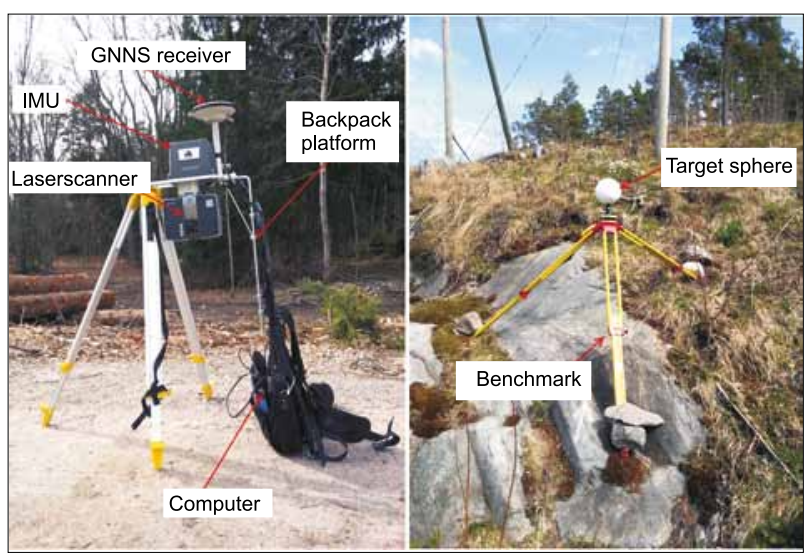

Fig. 6. The MLS system Akhka R2 (left) and a white sphere adjusted above the benchmark 95011 (right) et al. (2014), which is an updated version from its predecessor ROAMER (Akhka R1), presented by Kukko et al. (2012) and Kaartinen et al. (2013). The main instruments of the Akhka R2 are laser scanner (Faro Focus 3D), IMU system (NovAtel UIMU-LCI) and GNSS receiver (NovAtel Flexpak6). Additionally, the innovative backpack platform was rebuilt for Akhka R2, making it lighter and more practical to use in the field measurements (see Fig. 6, left).

The benchmarks were observed twice back and forth. White spheres (diameter $198.8 \mathrm{~mm}$ ) were adjusted directly above the benchmarks by using traditional tripods (Fig. 6, right). Centering and adjustment of the spheres were made the same way as the static GNSS/ GPS antennas.

The MLS measurement was performed from the backpack platform, meaning that the movement of the MLS system was made on foot. While walking the movement speed is naturally slower than with a vehicle, but a better coverage for the observations is achieved, since the laser scanner has more time to collect observations from the spheres. Additionally, with the backpack method one can carry the MLS system into the places which would be inaccessible with a vehicle, like the benchmark 971007 (Fig. 2).

For obtaining the actual height of the benchmark, the height offset (the height from the top of the benchmark to the centre of the sphere) needs to be subtracted from the laser scanned height. The height between the centre of the sphere and the top 
Table 7. Results of the MLS measurements

\begin{tabular}{|l|c|c|c|c|}
\hline \multirow{2}{*}{ Height values } & $95011(1)$ & $971007(1)$ & $95011(2)$ & $971007(2)$ \\
\cline { 2 - 5 } & $n=71$ (observations) & $n=2356$ & $n=211$ & $n=2635$ \\
\hline Laser scanning & $33.20258 \mathrm{~m}$ & $43.22296 \mathrm{~m}$ & $33.21880 \mathrm{~m}$ & $43.25107 \mathrm{~m}$ \\
\hline Offset & $1.10330 \mathrm{~m}$ & $1.47259 \mathrm{~m}$ & $1.10330 \mathrm{~m}$ & $1.47259 \mathrm{~m}$ \\
\hline Geoid height & $18.26791 \mathrm{~m}$ & $18.26325 \mathrm{~m}$ & $18.26791 \mathrm{~m}$ & $18.26325 \mathrm{~m}$ \\
\hline Levelled height (MLS) & $13.83137 \mathrm{~m}$ & $23.48712 \mathrm{~m}$ & $13.84759 \mathrm{~m}$ & $23.51523 \mathrm{~m}$ \\
\hline Height difference & \multicolumn{3}{|c|}{$9.65575 \mathrm{~m}$} & $9.66764 \mathrm{~m}$ \\
\hline Average value & \multicolumn{4}{|c|}{$9.66170 \mathrm{~m}$} \\
\hline
\end{tabular}

of the benchmark was obtained by known attributes of the sphere and measured slant heights. The geoid heights of the benchmarks were calculated with bilinear interpolation from the latest geoid model of Finland, FIN2005N00 (Bilker-Koivula, Ollikainen 2009; Bilker-Koivula 2010).

The heights and results of the MLS measurement are presented in Table 7. The symbol $n$ in the title bar denotes the number of observations from the spheres in each case. As seen from the Figure 2, the trajectories pass close to the benchmark 971007 while the benchmark 95011 is left further away from the trajectories. For this reason there are more observations from the benchmark 971007.

The MLS system consists of several different surveying instruments, meaning the total uncertainty budget accumulates from several sources. The sources with uncertainties are presented in Table 8 .

Figure 4 showed that the results from the VRS differed more on the benchmark 971007 due to the unfavorable environment for the satellite measurements. Table 8 indicates the same phenomenon as the uncertainty increases from $\pm 8.11 \mathrm{~mm}$ to $\pm 14.06 \mathrm{~mm}$. Although the uncertainties of the geoid model were eliminated for the reasons expressed in the GNSS measurements, the total uncertainty of the MLS system was $\pm 16.25 \mathrm{~mm}$.

Table 8. Measurement uncertainties of the MLS

\begin{tabular}{|l|c|}
\hline \multicolumn{1}{|c|}{ Source } & Uncertainty (RMS) \\
\hline Laser scanner-GNSS-IMU & $\begin{array}{c} \pm 8.11 \mathrm{~mm}(95011) \text { and } \\
14.06 \mathrm{~mm}(971007)\end{array}$ \\
\hline $\begin{array}{l}\text { Centre of the sphere- } \\
\text { benchmark }\end{array}$ & $\pm 0.50 \mathrm{~mm}$ \\
\hline $\begin{array}{l}\text { Centre of the sphere-point } \\
\text { cloud }\end{array}$ & $\begin{array}{c} \pm 0.30 \mathrm{~mm} \mathrm{(95011)} \mathrm{and} \\
0.58 \mathrm{~mm}(971007)\end{array}$ \\
\hline Geoid model & - \\
\hline Total (RSS) & $\pm 16.25 \mathrm{~mm}$ \\
\hline
\end{tabular}

\section{Discussion - analysis of the results}

The height differences of the benchmarks and the measurement uncertainties of the techniques are presented in Table 9. As expected, the lowest uncertainty was achieved with the precise levelling, where the uncertainty was significantly better than with the static GPS. However, the surroundings of the benchmarks were challenging for the satellite measurements and only GPS satellites were observed. In addition, the uncertainty of the precise levelling is slightly misleading, since the cumulated effect of the levelling uncertainty does not pile up in such a short levelling line. Similarly, the short distance is unfavorable to the GNSS measurement, which would gain over longer distances.

Table 9. Final results of the field tests

\begin{tabular}{|l|c|c|c|}
\hline $\begin{array}{c}\text { Height } \\
\text { determination } \\
\text { technique }\end{array}$ & $\begin{array}{c}\text { Height } \\
\text { difference } \\
\text { (HD) } \\
\text { between the } \\
\text { benchmarks, } \\
9.6+\mathrm{m}\end{array}$ & $\begin{array}{c}\text { Measurement } \\
\text { uncertainties }\end{array}$ & $\begin{array}{c}\text { Extreme } \\
\text { values }\end{array}$ \\
\hline $\begin{array}{l}\text { Precise } \\
\text { levelling (PL) }\end{array}$ & $61.14 \mathrm{~mm}$ & $\pm 0.27 \mathrm{~mm}$ & $\begin{array}{c}\text { Lowest } \\
\text { uncertainty }\end{array}$ \\
\hline Static GPS I & $60.66 \mathrm{~mm}$ & $\pm 3.44 \mathrm{~mm}$ & $\begin{array}{c}-0.48 \mathrm{~mm} \\
\text { from PL }\end{array}$ \\
\hline Static GPS II & $62.26 \mathrm{~mm}$ & $\pm 3.73 \mathrm{~mm}$ & $\begin{array}{c}1.12 \mathrm{~mm} \\
\text { from PL }\end{array}$ \\
\hline $\begin{array}{l}\text { Static GPS } \\
\text { avg. }\end{array}$ & $61.46 \mathrm{~mm}$ & $\pm 3.59 \mathrm{~mm}$ & $\begin{array}{c}0.32 \mathrm{~mm} \\
\text { from PL }\end{array}$ \\
\hline $\begin{array}{l}\text { VRS } \\
\text { (average) }\end{array}$ & $71.62 \mathrm{~mm}$ & $\pm 12.46 \mathrm{~mm}$ & Largest HD \\
\hline $\begin{array}{l}\text { Mobile laser } \\
\text { scanning I }\end{array}$ & $55.75 \mathrm{~mm}$ & $\pm 16.25 \mathrm{~mm}$ & Lowest HD \\
\hline $\begin{array}{l}\text { Mobile laser } \\
\text { scanning II }\end{array}$ & $67.64 \mathrm{~mm}$ & $\pm 16.25 \mathrm{~mm}$ & $\begin{array}{c}\text { Largest } \\
\text { uncertainty }\end{array}$ \\
\hline $\begin{array}{l}\text { Mobile laser } \\
\text { scanning } \\
\text { (average) }\end{array}$ & $61.70 \mathrm{~mm}$ & $\pm 16.25 \mathrm{~mm}$ & $\begin{array}{c}0.56 \mathrm{~mm} \\
\text { from PL }\end{array}$ \\
\hline
\end{tabular}


The result from the VRS measurement was calculated as an average value from 50 independent height differences. The observed height values were quite scattered (Fig. 4), which led to the total uncertainty of $\pm 12.46 \mathrm{~mm}$. The average result differed one centimeter from the precise levelling and the static GPS.

The average value from the MLS measurements agreed well with the precise levelling and the static GPS, since the results were within $0.5 \mathrm{~mm}$ from each other. However, there was a significant difference $(>10$ $\mathrm{mm}$ ) between the two MLS measurements. This agrees with the measurement uncertainty $( \pm 16.25 \mathrm{~mm})$ of the MLS system.

Uncertainties in the geoid model were mostly eliminated in this research. The geoid models (e.g. FIN2005N00), have an uncertainty of $20 \mathrm{~mm}$ in the absolute accuracies (Bilker-Koivula 2010). This cannot be ignored in the case of larger field tests. The uncertainties in the geoid model does not affect to the uncertainties of the precise levelling, only to the techniques which are related to ellipsoidal heights and need to be converted to the physical heights.

\section{Conclusions and future studies}

This research highlighted the differences of the studied techniques and the possibilities they presents regarding the height determination, but in such a small test area the results are too biased in favor of the precise levelling. Precision and repeatability were practically the only measurands we were able to compare. Time effectiveness, error propagation, reliability and distance dependency are topics to be studied in a more extensive (existing precise levelling network) test area.

In a more extensive test we should use all available navigation satellite systems with GNSS levelling. With the additional systems (Galileo, BeiDou) as with the ongoing GPS-modernization the number of the positioning satellites and signals will increase significantly by the end of the decade. This would improve the observations in more challenging environments.

The method for the MLS measurements in an extended test would not be on foot as in this research, while it was merely a special case to get the best possible accuracy out of the MLS at the expense of the measurement rate. The platform for the MLS measurements would be a vehicle.

A vehicle could also be used to improve the time efficiency of the precise levelling. Motorized levelling has been widely used for decades e.g. in Sweden and
Germany, but it has never been put into service in Finland. One additional source of uncertainty is the effect of the heated engine of the vehicle, which will change the refraction when the line-of-sight is passing the heated car hood. With modern electric cars this can be avoided. A semi-automated motorized levelling would be one topic to be studied in the future.

Based on this pilot project we cannot exclude any of the techniques tested here. Some of them are already used to replace lower-order levelling. There are possibilities to improve their accuracy, one of the topics being the geoid model. The latest gravity satellite missions Gravity Recovery And Climate Experiment (GRACE 17.3.2002-present) and Gravity field and steady-state Ocean Circulation Explorer (GOCE 17.3.2009-11.11.2013) have improved the determination of the longer wavelengths in the geoid modelling, thus improving the geoid models and thereby satellitebased techniques.

The working group for Geoid and Height System of the Nordic Geodetic Commission is developing a more precise Nordic geoid model and new national models are developed in the FGI. The working group also investigates the possibilities for a geoid model with sub-cm accuracy in the future. Such a model would be sufficient for height determination and maintenance of a national height system. We will continue the research with studying the geoid models and planning similar but more extensive field test, where additional techniques, like airborne laser scanning, could be included.

\section{Acknowledgements}

This research is based on a Master's thesis by Timo Saari (2013). The work of Saari was supported by a grant of Vilho, Yrjö and Kalle Väisälä Foundation, and the ESA-MOST Dragon 3 contract No. 4000110315/14/I-BG. MLS system development has been funded by Academy of Finland, Centre of Excellence in Laser Scanning Research (CoE-LaSR, 272195), "Science and Technology Towards Precision Forestry" (FGI and Univ. Helsinki), and "Intelligent roadside modeling” (Aalto), Finnish Funding Agency for Technology and Innovation, through projects "Development of Automatic, Detailed 3D Model Algorithms for Forests and Built Environment" (FGI), "Developing mapping and modeling approaches as a part of flood risk management business" (FGI, Aalto and Univ. Turku), "Intelligent built environment ÄRY” (FGI), and RYM-SHOK "Energizing Urban Ecosystems" (Aalto, FGI). 


\section{References}

Ågren, J.; Svensson, R. 2007. Postglacial land uplift model and system definition for the new Swedish height system RH 2000. LMV-Rapport 2007:4, Reports in Geodesy and Geographical Information Systems. Gävle, Sweden. ISSN 280-5731.

Amos, M. 2010. New Zealand vertical datum 2009 - a geoid based height system for the unification of disparate local vertical datums, in XXIV FIG (International Federation of Surveyors) International Congress 2010, 11-16 April 2010, Sydney, Australia [online], [cited 6 July 2015]. Available from Internet: http://www.fig.net/pub/fig2010/papers/ ts10i\%5Cts10i_amos_3884.pdf

Becker, J. 1999. History and evolution of height determination techniques especially in Sweden, in M. Lilje (Ed.). Geodesy and Surveying in the Future - The Importance of Heights. ISSN 0280-5731.

Bilker-Koivula, M. 2010. Development of the Finnish height conversion surface FIN2005N00, Nordic Journal of Surveying and Real Estate Research 7(1): 76-88. ISSN 1459-5877.

Bilker-Koivula, M.; Ollikainen, M. 2009. Suomen geoidimallit ja niiden käyttäminen korkeuden muunnoksissa, Research Notes of the Finnish Geodetic Institute 29 (in Finnish). ISBN 978951-711-259-8. ISBN 978-951-711-260-4. ISSN 0787-9172.

Forsberg, R.; Strykowski, G.; Solheim, D. 2004. NKG-2004 geoid of the Nordic and Baltic area, in Proceedings from the International Association of Geodesy Conference: Gravity, Geoid and Satellite Gravity Missions, 30 August - 3 September 2004, Porto, Portugal.

Häkli, P.; Koivula, H.; Puupponen, J. 2008. Assessment of practical 3-D geodetic accuracy for static GPS surveying, in FIG (International Federation of Surveyors) Working Week 2008: Reliability of Positioning and Measurement Technology, 14-19 June 2008, Stockholm, Sweden [online], [cited 6 July 2015]. Available from Internet: http://www.fig.net/pub/fig2008/papers/ts03h/ts03h_01_hakli_etal_2994.pdf

Hyyppä, J.; Wagner, W.; Hollaus, M.; Hyyppä, H. 2009. Airborne laser scanning, 199-211 in T. Warner, D. Nellis, G. Foody (Eds.). The SAGE Handbook of Remote Sensing. Bangalore, India: Replika Press Pvt Ltd. Session 3: Digital Sensors and Image Characteristics. ISBN 978-1-4129-3616-3.

Kaartinen, H.; Hyyppä, J.; Kukko, A.; Lehtomäki, M.; Jaakkola, A.; Vosselman, G.; Elberink, S. O.; Rutzinger, M.; Pu, S.; Vaaja, M. 2013. Mobile mapping - road environment mapping using mobile laser scanning, EuroSDR - European Spatial Data Research 62: 49-95 [online], [cited 6 July 2015]. Available from Internet: http://www.eurosdr.net/sites/default/files/uploaded_files/62_1.pdf

Kallio, U.; Poutanen, M. 2013. Local ties at fundamental stations, in Z. Altamimi, X. Collilieux (Eds.). International Association of Geodesy Symposia 138: Reference Frames for Applications in Geosciences. Springer Verlag.

http://dx.doi.org/10.1007/978-3-642-32998-2_23

Karila, K.; Karjalainen, M.; Hyyppä, J.; Koskinen, J.; Saaranen, V.; Rouhiainen, P. 2013. A comparison of precise leveling and persistent scatterer sar interferometry for building subsidence rate measurement, ISPRS International Journal of Geo-Information 2(3): 797-816.

http://dx.doi.org/10.3390/ijgi2030797

Kharaghani, G. A. 1987. Propagation of refraction errors in trigonometric height traversing and geodetic levelling: $\mathrm{PhD}$ Dissertation. Department of Geodesy and Geomatics Engineering, University of New Brunswick, Canada.
Kukkamäki, T. J. 1938. Über die nivillitische Refraktion [About the levelling refraction], Publications of the Finnish Geodetic Institute 25 (in German). Helsinki, Finland: Valtioneuvoston kirjapaino.

Kukko, A.; Kaartinen, H.; Hyyppä, J.; Chen, Y. 2012. Multiplatform mobile laser scanning: usability and performance, Sensors 12(9): 11712-11733. ISSN 1424-8220.

http://dx.doi.org/10.3390/s120911712

Lehmuskoski, P.; Saaranen, V.; Takalo, M.; Rouhiainen, P. 2008. Bench mark list of the third levelling of Finland, Publications of the Finnish Geodetic Institute 139. ISBN 978-951-711-265-9. ISBN 978-951-711-264-2. ISSN 0085-6932.

Lemmens, M. 2012. GNSS positioning: status and features, GIM International 26(10): 18-25. ISSN 1566-9076.

Liang, X.; Kukko, A.; Kaartinen, H.; Hyyppä, J.; Yu, X.; Jaakkola, A.; Wang, Y. 2014. Possibilities of a personal laser scanning system for forest mapping and ecosystem services, Sensors 14(1): 1228-1248. http://dx.doi.org/10.3390/s140101228

Lidberg, M.; Johansson, J. M.; Scherneck, H. -G.; Davis, J. L. 2007. An improved and extended GPD-derived 3D velocity field of the glacial Isostatic adjustment (GIA) in Fennoscandia, Journal of Geodesy 81(3): 213-230.

http://dx.doi.org/10.1007/s00190-006-0102-4

Natural Resources Canada. 2015. Height Reference System Modernization [online], [cited 6 July 2015]. Earth Sciences. Available from Internet: http://webapp.geod.nrcan.gc.ca/ geod/hmod/hmod.php\#cgvd2013

Nelson, R.; Krabill, W.; Maclean, G. 1984. Determining forest canopy characteristics using airborne laser data, Remote Sensing of Environment 15(3): 201-212. ISSN 00344257. http://dx.doi.org/10.1016/0034-4257(84)90031-2

Ojanen, O. 1996. Refraction in a layered medium with application to geodesy and to atmospheric acoustics: $\mathrm{PhD}$ Dissertation. Department of Surveying, Helsinki University of Technology. Acta Polytechnica Scandinavica, Civil Engineering and Building Construction Series 104. Helsinki, Finland: Finnish Academy of Technology. ISBN 951-666-477-6. ISSN 0355-2705.

Ollikainen, M. 1997. Determination of orthometric heights using GPS Levelling: PhD Dissertation. University of Helsinki. Helsinki, Finland: Oy Edita Ab. ISBN 951-711-210-6. ISSN 0085-6932.

Poetzschke, H. 1980. Motorized leveling at the National Geodetic Survey, NOAA Technical Memorandum NOS NGS 26. Rockville, Maryland, USA: US National Geodetic Survey [online], [cited 6 July 2015]. Available from Internet: http:// www.ngs.noaa.gov/PUBS_LIB/MotorizedLeveling_at_the_ National_Geodetic_Survey_TM_NOS_NGS26.pdf

Pollinger F.; Astrua, M.; Bauch, A.; Bergstrand, S.; Görres, B.; Jokela, J.; Kallio, U.; Koivula, H.; Kuhlmann, H.; Kupko, V.; Meiners-Hagen, K.; Merimaa, M.; Niemeier, W.; Neyezhmakov, P.; Poutanen, M.; Saraiva, F.; Schön, S.; van den Berg, S. A.; Wallerand, J-P.; Zucco, M. 2015. Metrology for long distance surveying - a joint attempt to improve traceability of long distance measurements, International Association of Geodesy Symposia 143. Springer.

Saari, T. 2013. Valtakunnalliset korkeudenmääritysmenetelmät [Height determination techniques for national height systems] (in Finnish): Master's thesis. Department of Real Estate, Planning and Geoinformatics, Aalto University, Finland.

Schreier, H.; Lougheed, J.; Tucker, C.; Leckie, D. 1985. Automated measurements of terrain reflection and height variations 
using an airborne infrared laser system, International Journal of Remote Sensing 6(1): 101-113.

http://dx.doi.org/10.1080/01431168508948427

Trimble. 2015. Trimble TX8 [online], [cited 6 July 2015]. Available from Internet: http://trl.trimble.com/docushare/dsweb/ Get/Document-687693/022516-014C_Trimble_TX8_ DS_0415_LR.pdf

Vestøl, O. 2005. Determination of postglacial land uplift in Fennoscandia from leveling, tide-gauges and continuous GPS stations using least squares collocation, Journal of Geodesy 80(5): 248-258. http://dx.doi.org/10.1007/s00190-006-0063-7

Timo SAARI. M.Sc. in Geodesy, 2013, Aalto University. Research Scientist, Department of Geodesy and Geodynamics, Finnish Geospatial Research Institute (FGI). Research interests: height systems, height determination techniques, gravity, geoid modelling, GOCE.

Markku POUTANEN. Prof. Head of the Department of Geodesy and Geodynamics, Finnish Geospatial Research Institute (FGI). Research interests: land uplift, crustal deformation, reference systems, satellite-based positioning systems.
Veikko SAARANEN. Lic.Phil. Specialist Research Scientist, Department of Geodesy and Geodynamics, Finnish Geospatial Research Institute (FGI). Research interests: reference systems, precise levelling development, VLBI.

Harri KAARTINEN. D.Sc. Research Manager, Department of Remote Sensing and Photogrammetry, Finnish Geospatial Research Institute (FGI). Research interests: mobimap, mobile laser scanning, mobile mapping platforms.

Antero KUKKO. D.Sc. Research Manager, Department of Remote Sensing and Photogrammetry, Finnish Geospatial Research Institute (FGI). Research interests: mobimap, mobile laser scanning, mobile mapping platforms.

Sonja LAHTINEN. M.Sc. Research Scientist, Department of Geodesy and Geodynamics, Finnish Geospatial Research Institute (FGI). Research interests: reference systems, satellite-based positioning systems. 